\title{
Predicting Locations of Defects in the Solidification Process for Large-Scale Cast Steel*
}

\author{
Nao-Aki NODA**, Shuji EGAWA**, Yasunori TASHIRO*** \\ and Kouji TAKENOUCHI*** \\ ${ }^{* *} K y u s h u$ Institute of Technology, Department of Mechanical Engineering \\ Sensui-cho, Tobata-ku, Kitakyushu, 804-8550 Japan \\ E-mail:noda@mech.kyutech.ac.jp \\ *** Japan Casting \& Forging Corporation \\ 46-59 Ooazanakabaru-sakinohama, Tobata-ku, Kitakyushu,804-8550, Japan
}

\begin{abstract}
The large-scale cast steel has been used in broad fields of industries, such as power generation, construction, vessels, and automobiles. In the solidification process of a hummer used for press machine, for example, sometimes defects such as shrinkage cavity, segregation and cracks appear at hummer's surface. Shrinkage cavity and segregation can be predicted by performing non-steady state heat transfer analysis; and therefore such two types of defects can be eliminated by using chills which control solidification process. However, uneven cooling rates at different regions of the large-scale cast steel generate thermal stresses, which cause solidification cracks, between the chills. For causing those cracks, thermal stress may be important; however, there have been few studies for this thermal stress analysis. In this study, a three dimensional thermal elastic-plastic stress analysis has been performed by using finite element method in connection with three dimensional non-steady state heat transfer analysis, including interaction between the temperature and stress field. The results provide further understanding of the observed solidification crack failure for large-scale cast steel.
\end{abstract}

Key words: Thermal Stress, Finite Element Method, Plasticity, Cast Steel, Crack

\section{Introduction}

The large-scale cast steel products have been used as fundamental components of structures in broad fields of industries such as power generation, construction, vessels, and automobiles. To produce such large-scale product, experienced engineers and technicians are usually conducting casting plans without using established theory although recently such senior engineers are decreasing in most Japanese companies. In the large-scale cast steel, it is known that there are three types of defects called shrinkage cavity, segregation and crack-type defects. They are known to appear more often compared to the case of small-scale, and causing a lot of money for repairing. Here, shrinkage cavity appears because of lack of molten steel, and segregation appears because of the specific weight difference of chemistry ingredients. In recent years, non-steady state heat transfer analyses [1], [2] are used as powerful tools On the basis of such simulations and recent studies, it is found that two types of defects, shrinkage cavity and segregation, may be eliminated successfully by arranging chills and controlling solidification process. This is because such

*Received 19 Dec., 2008 (No. T1-07-0264) Japanese Original : Trans. Jpn. Soc. Mech. Eng., Vol.73, No.734, A (2007), pp.1136-1143 (Received 26 Mar., 2007) [DOI: 10.1299/jcst.3.242] 
defects may be controlled by cast temperature to simulate the solidification processes in order to predict such defects.

On the other hand, crack-type defects cannot be controlled by cast temperature and therefore they cannot be predicted through such heat transfer analysis. It is known that such crack-type defects are often encountered between the chills although they are largely depending on the geometries of casting product and casting material. Since numerical simulations of crack-type defects are so complicated and mechanical properties of casting steel are not well-known at high temperature, predictions of such crack-type defects have not been studied successfully until now. In this paper, therefore, the finite element method will be applied to a sample problem as shown in Fig.1. Figure1 shows a hummer used for press machinery, which manufactures bodies of automobiles. In this study, we will focus on predicting cracks for this hummer. Here, a three-dimensional thermal elastic-plastic stress analysis has been performed by using finite element method in connection with three dimensional non-steady state heat transfer analysis, including interaction between the temperature and stress field [3]. Then, the thermal stress, which may cause crack defects, will be investigated with varying the spacing of chills and chill shape.

\section{Method of analysis}

\subsection{Modeling of research object}

Figure 2 (a) shows a hummer used for press machine, which manufactures bodies of automobiles. The hummer has dimensions about $2500 \mathrm{~mm} \times 2000 \mathrm{~mm} \times 3000 \mathrm{~mm}$ and weighs about 30t. Figure 2 (b) shows examples of arrangement of chills controlling shrinkage cavities and segregations, which may appear at hummer surface. However, in the preliminary analysis it is found that real chill arrangement as shown in Fig.2 (b) is too complicated, and not suitable investigating the mechanism of crack-type defects. Therefore in this paper two chills model as shown in Fig.2 (c), (d) will be considered. Then, the effect of location of chills upon the thermal stress will be discussed.

\subsection{Dimensions of two chill models Model}

Figure 3 indicates mesh pattern where five components are included; sand mold and heat insulation are in Fig. 3 (a), and cast steel, two chills, and keep warming material are in Fig. 3 (b). This analysis model includes five parts, heat insulation, keeping-warm material, cast steel, sand mold and two chills. As shown in Fig. 3, tetrahedral elements are mainly used; however hexahedral elements with fine mesh are applied for the under-part of cast steel and the chills in order to deal with initial large temperature difference more than $1000^{\circ} \mathrm{C}$.

Figure 4 (a), (b) shows arrangement and shape of two chills. In this study, two types of chills are considered; one is two cubic chills model whose dimensions are $a^{2} \times t$, and the other is two cylinder chills model whose dimensions are $\pi \times(d / 2)^{2} \times t$. The chill spacing is assumed as $l=30 \mathrm{~mm}, 70 \mathrm{~mm}, \infty$ where $l=\infty$ is corresponding to single chill. When $l=70 \sim 90 \mathrm{~mm}$, it is known that crack-type defects are more often observed between cubic chills compared to cylindrical chills. Figure 4 (c) (d) shows mesh divisions for $l=70$

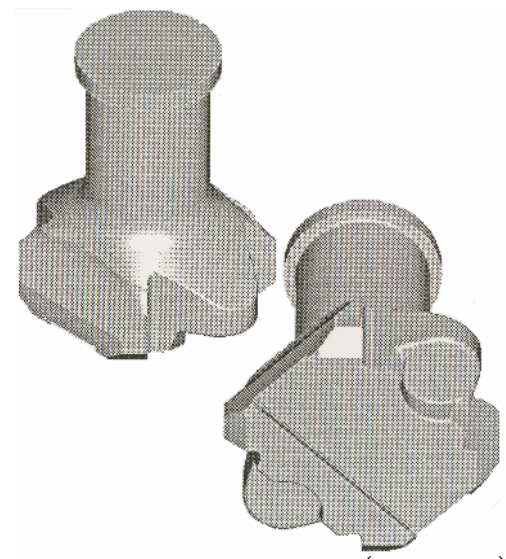

Fig.1 Research object (Hummer) 

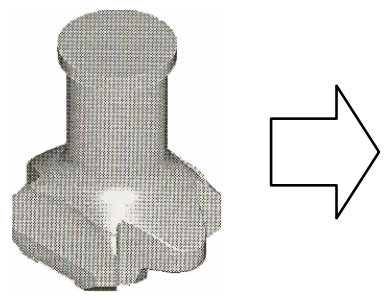

(a) Hummer

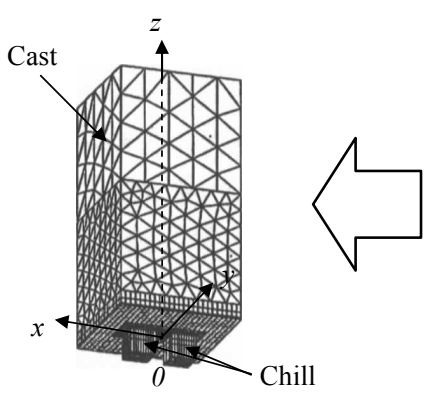

(d) Mesh pattern at cast and chill

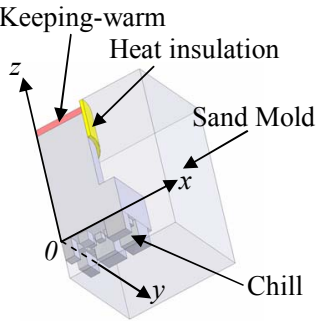

(b) Analysis model-1 (quarter)

Fig.2 Research object

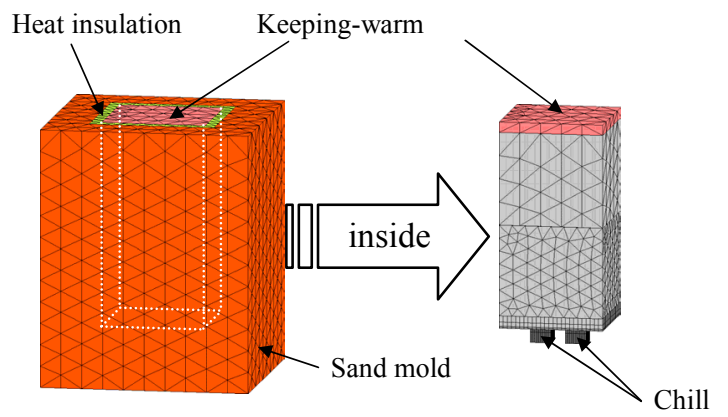

(a) Mesh pattern of all parts

(b) Mesh pattern of cast steel, chills,

Fig.3 Mesh pattern of FEM model

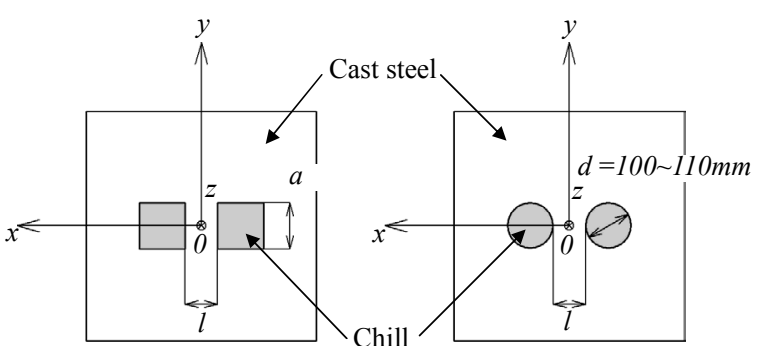

(a) Cubic chills

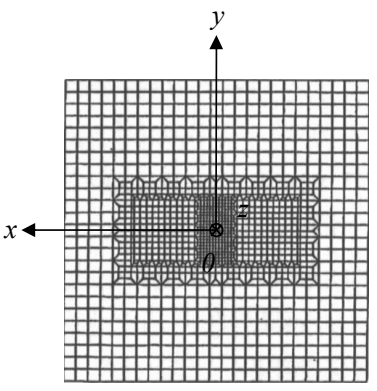

(c) Cubic chills $(l=70 \mathrm{~mm})$ (b) Cylinder chills

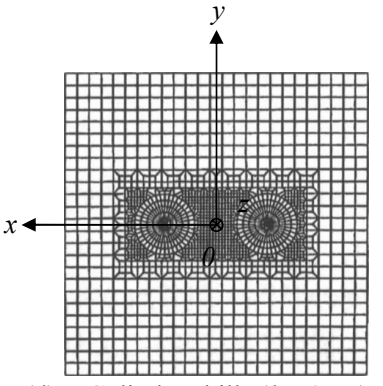

(d) Cylinder chills $(l=70 \mathrm{~mm})$

Fig.4 Disposition of chills 
$\mathrm{mm}$. Fine mesh divisions are applied between two chills because high accuracy is required. Fine mesh divisions are applied between two chills because high accuracy is required.

\subsection{Material Properties}

Assume 2Cr-Mo steel is used for cast steel and chills, and silica sand is used for sand mold. Table 1 shows chemical compositions of cast steel, and Table 2 shows material properties of cast steel, chill, sand mold, keeping-warm material, and heat insulation. The asterisk means those material properties are depending on temperature. Material properties of cast steel are indicated in Fig.5-9 for Young's modulus, yield stress, coefficient of linear expansion, thermal conductivity, and specific heat as function of temperature. Also, thermal conductivity of sand mold is shown in Fig. 10 [4]. Material properties of 2Cr-Mo steel are extrapolated to the level of below the solidification from the data of just above the solidification. To consider the latent heat, the apparent capacity method [5] is applied. Then, the latent heat is included in the specific heat of the material assuming that the latent heat $272.4 \mathrm{~kJ} / \mathrm{kg}$ is released uniformly between the liquids-solid range $\left(1462^{\circ} \mathrm{C}-1503^{\circ} \mathrm{C}\right)$.

In this analysis, simple perfect bonded conditions are assumed between the cast steel, chills, keep-warming material, and heat insulation. Then, chill's expansion causes compressive stress around the contact region. Therefore the coefficient of linear expansion and Poisson's ratio are assumed to be zero, and Young's modulus is assumed as $1 \mathrm{KPa}$ so that chills, keep-warming material, and heat insulation provide only thermal effects. For elastic-plastic analysis, the elastic material is assumed as perfect elastic material because work-hardening effect is so small at high temperature.

\subsection{Boundary and Initial Conditions}

For large-scale cast steel, from several hours to several ten hours are necessary for solidification process, but only a few minutes for casting process. Therefore the casting time difference to fill in the under and upper parts in sand mold is so small that heat transfer may be neglected during casting. In other words, cast steel is assumed to be filled in sand mold without delay at the time of zero in this study. We put initial temperature of cast steel is $1530^{\circ} \mathrm{C}$, and initial temperature of keeping-warm material and atmosphere is $20^{\circ} \mathrm{C}$ and others are $40^{\circ} \mathrm{C}$. We also assume that there is no-gap appearing between cast steel, chills, sand mold and others. Heat is transferred through convection from the contact surfaces with heat transfer coefficients given in Table 2. On the other hand, heat is transferred through natural heat convection from the surfaces of the sand mold and heat insulation to air.

In this study, first, heat convection analysis will be performed from the initial and boundary conditions described above; then, temperature distribution will be obtained. Next, thermal stress analysis [6] will be performed under the given temperature. Given stress and temperature distributions will be used for determining next initial and boundary conditions in the consecutive step. Those procedures will be performed in each step of heat convection and thermal stress analyses.

\section{The Results of Thermal Stress between Two Chills}

\subsection{Position of maximum stress $\sigma_{x}$ which may cause crack-type defects}

If two chills are arranged as shown in Fig.4, it is known that crack-type of defects may appear perpendicularly to the x-axis. Therefore we consider the value of $\sigma_{x}$ which may cause crack initiation. Figure 11 shows $\sigma_{x}$ vs. time relationship when spacing $l=70 \mathrm{~mm}$. The maximum $\sigma_{x}$ appears around $x=15 \mathrm{~mm}$ for cylinder chills. In Fig.11 the $(x, y)$ coordinate is fixed at those positions and $\mathrm{z}$ coordinate is changed as $z=0 \mathrm{~mm}$, $5 \mathrm{~mm}, 10 \mathrm{~mm}, 30 \mathrm{~mm}$. From Fig.11, it is seen that $\sigma_{x}$ takes maximum values at $z \cong 5 \mathrm{~mm}-10 \mathrm{~mm}$. In the following discussion, therefore we will focus on a thermal stress $\sigma_{x}$ at $z=10 \mathrm{~mm}$.

Table 1 Chemical compositions of cast steel (2Cr-Mo Alloy [wt\%])

\begin{tabular}{|c|c|c|c|c|c|c|c|c|c|c|}
\hline $\mathrm{C}$ & $\mathrm{Si}$ & $\mathrm{Mn}$ & $\mathrm{P}$ & $\mathrm{S}$ & $\mathrm{Cu}$ & $\mathrm{Ni}$ & $\mathrm{Cr}$ & $\mathrm{Mo}$ & $\mathrm{V}$ & $\mathrm{Al}$ \\
\hline 0.15 & 0.38 & 0.6 & 0.008 & 0.008 & 0.04 & 0.15 & 2.11 & 0.91 & 0.007 & 0.008 \\
\hline
\end{tabular}


Table 2 Material properties of cast steel, chill, sand mold, keeping-warm material, and heat insulation

\begin{tabular}{|c|c|c|c|c|c|}
\hline & Cast steel & Chill & Sand mold & $\begin{array}{l}\text { Keeping- } \\
\text { warm } \\
\text { material }\end{array}$ & $\begin{array}{l}\text { Heat } \\
\text { insulation }\end{array}$ \\
\hline $\begin{array}{l}\text { Mass density } \\
{\left[\times 10^{3} \mathrm{~kg} / \mathrm{m}^{3}\right]}\end{array}$ & \multicolumn{2}{|l|}{7.85} & 1.7 & 0.15 & 1.1 \\
\hline $\begin{array}{l}\text { Young's modulus } \\
{[\mathrm{MPa}]}\end{array}$ & $\begin{array}{c}*(1.225 \sim 205800) \\
\quad(\text { See Fig. } 5)\end{array}$ & \multicolumn{4}{|c|}{0.001} \\
\hline Poisson's ratio & 0.3 & \multicolumn{4}{|c|}{0} \\
\hline $\begin{array}{l}\text { Yield stress } \\
{[\mathrm{MPa}]}\end{array}$ & $\begin{array}{c}*(0.490 \sim 215.746) \\
\quad(\text { See Fig. } 6)\end{array}$ & \multicolumn{4}{|c|}{0} \\
\hline $\begin{array}{c}\text { Coefficient of } \\
\text { linear expansion } \\
{\left[1 /{ }^{\circ} \mathrm{C}\right]}\end{array}$ & $\begin{array}{c}*(1.27 \sim 1.50) \\
\quad(\text { See Fig.7) }\end{array}$ & \multicolumn{4}{|c|}{0} \\
\hline $\begin{array}{c}\text { Thermal } \\
\text { conductivity } \\
{\left[\times 10^{-2} \mathrm{~W} / \mathrm{m}\right]}\end{array}$ & \multicolumn{2}{|c|}{$\begin{array}{c}*(2733.0 \sim 5191.0) \\
(\text { See Fig. } 8)\end{array}$} & $\begin{array}{c}*(66.98 \sim \\
124.8) \\
\text { (See Fig.10) } \\
\end{array}$ & 8.4 & 41.9 \\
\hline $\begin{array}{c}\text { Specific heat } \\
{[\mathrm{J} / \mathrm{kg} \cdot \mathrm{K}]}\end{array}$ & \multicolumn{2}{|c|}{$\begin{array}{c}*(460.47 \sim 1431.63) \\
(\text { See Fig. } 9)\end{array}$} & 964 & 922 & 1047 \\
\hline $\begin{array}{l}\text { Heat transfer } \\
\text { coefficient } \\
{\left[\mathrm{W} / \mathrm{m}^{2} \cdot \mathrm{K}\right]}\end{array}$ & \multicolumn{5}{|c|}{$\begin{array}{l}\text { 4144189.5(Cast steel-Chill, Heat insulation-Air) } \\
\text { 418.605(Cast steel-Sand mold, Chill-Sand mold, Sand mold-Keeping-warm material, } \\
\text { Sand mold-Heat insulation) } \\
\text { 41.8605(Cast steel-Keeping-warm material, Cast steel-Heat insulation) } \\
\text { 20.903025(Keeping-warm material, Heat insulation-Air) } \\
\text { 4.18605(Cast steel-Heat insulation) }\end{array}$} \\
\hline
\end{tabular}

* These properties are depending on temperature as shown Fig.5-10.

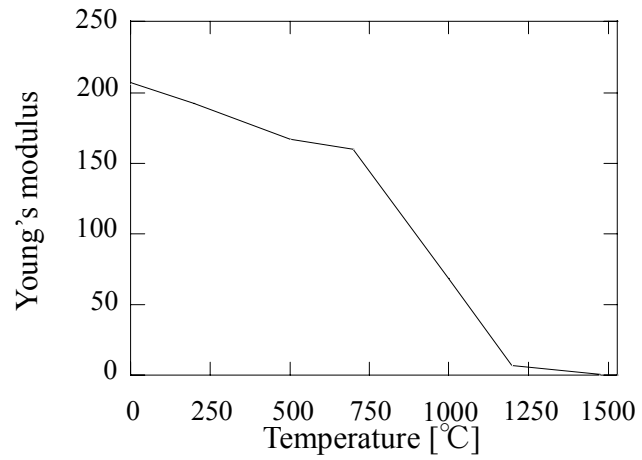

Fig.5 Young's modulus of cast steel

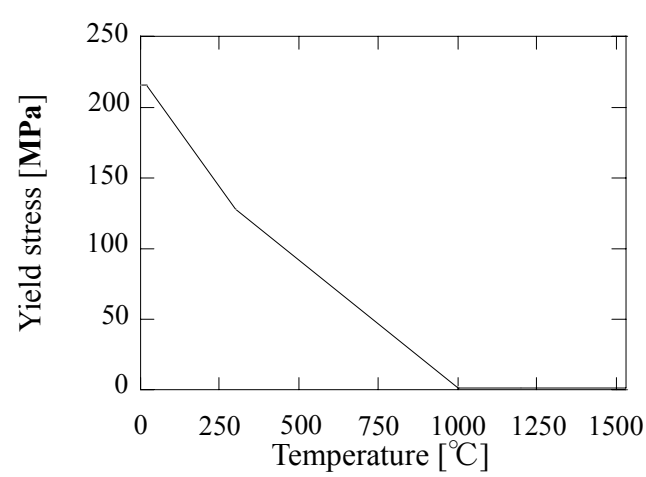

Fig.6 Yield stress of cast steel

At $z>0 \mathrm{~mm}, \sigma_{x}$ appears as a compressive stress at first during $500-1000 \mathrm{sec}$, and turns into a tensile stress with a maximum value at $1200 \mathrm{sec}$, and finally decreasing and becoming zero. During the beginning of solidification process, therefore, tensile stress appears near the contact surface, and compressive stress appears above the contact surface. With developing the solidification zone toward inside, the tensile stress zone is also going into inside [7]. The tensile stress is largely depending on chill's geometries. In Fig. 11 the temperature of cast steel changes from $1530^{\circ} \mathrm{C}$ at $\mathrm{t}=0 \mathrm{sec}$ to $1200^{\circ} \mathrm{C}$ at $\mathrm{t}=3600 \mathrm{sec}$. Under this range of temperature it should be noted that the yielding stress of cast steel is in the range $\sigma_{\text {yield }}=0.8-1.5 \mathrm{MPa}$. 
3.2 Thermal stress appearing between the chills in comparison with the yielding stress

Since the yielding stress of cast steel varies depending on its temperature, the largest stress does not always mean causing crack initiation. In other words, in order to predict the location of defects, it is important to consider the value of stress in comparison with the yielding stress. In this study, therefore, we will focus on the parameter $\sigma_{\text {eq }} / \sigma_{\text {yield }}$, which is the equivalent stress normalized by the yielding stress. Here, since cast steel is assumes as a perfect elastic-plastic body, $\sigma_{e q} / \sigma_{\text {yield }} \leqq 1$. If some portions are in the situation $\sigma_{e q} / \sigma_{\text {yield }}=$ unity for several times, cracks may appear at this portion. On the other hand, if $\sigma_{e q} / \sigma_{\text {yield }}$ is less than unity, cracks may not appear.

\subsection{Relationships between the thermal stress and spacing of two chills}

Figure 12 shows $\sigma_{e q} / \sigma_{\text {yield }}$ vs. time relation for spacing $l=30 \mathrm{~mm}$. Since the maximum stress $\sigma_{x}$ appears at $z=10 \mathrm{~mm}, \mathrm{z}$ is fixed as $z=10 \mathrm{~mm}$. These figures indicate crack may appear because $\sigma_{e q} / \sigma_{\text {yield }}=$ unity for a long time. Figure 13 shows $\sigma_{e q} / \sigma_{\text {yield }}$ vs. time

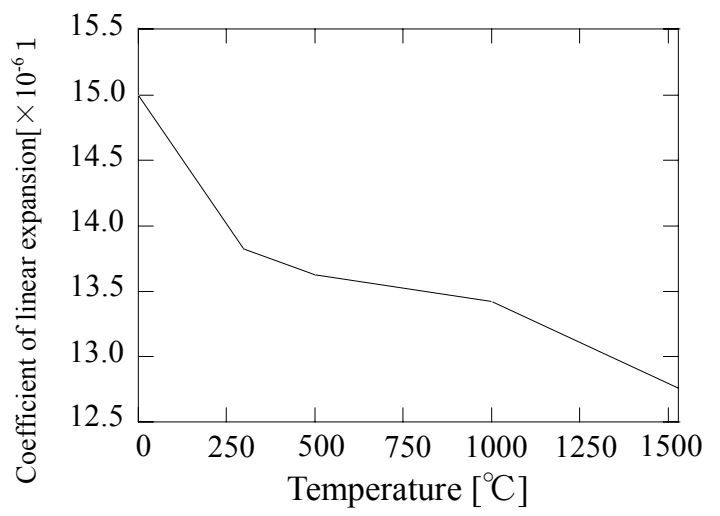

Fig.7 Coefficient of linear expansion of cast steel

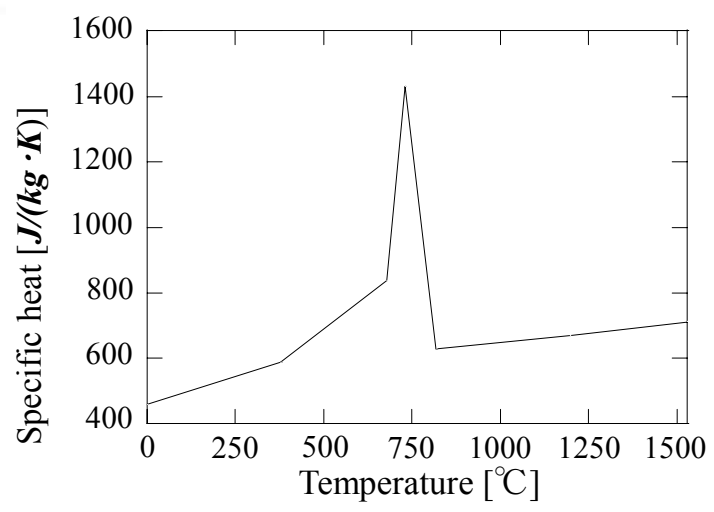

Fig.9 Specific heat of cast steel and chills

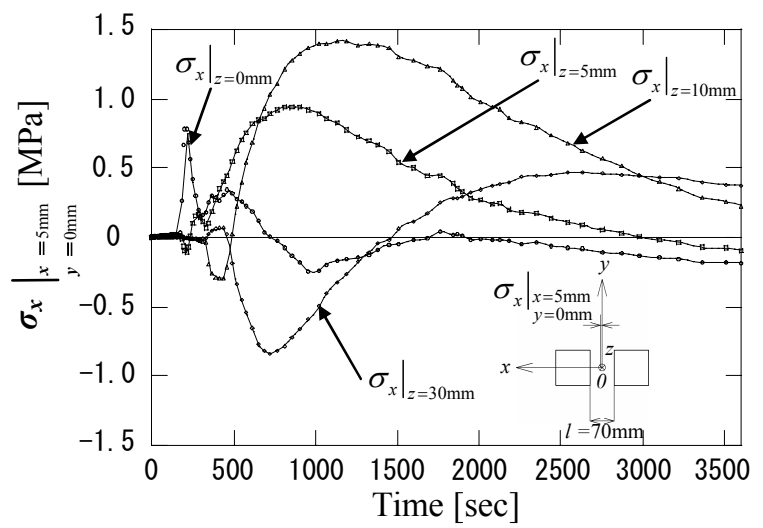

(a) $\sigma_{x}$ at $(\boldsymbol{x}, \boldsymbol{y})=(5,0)$ for cubic chills

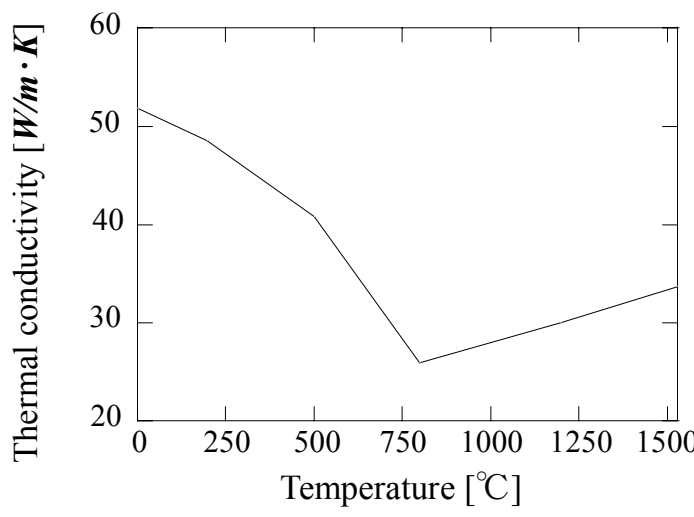

Fig.8 Thermal conductivity of cast steel and chills

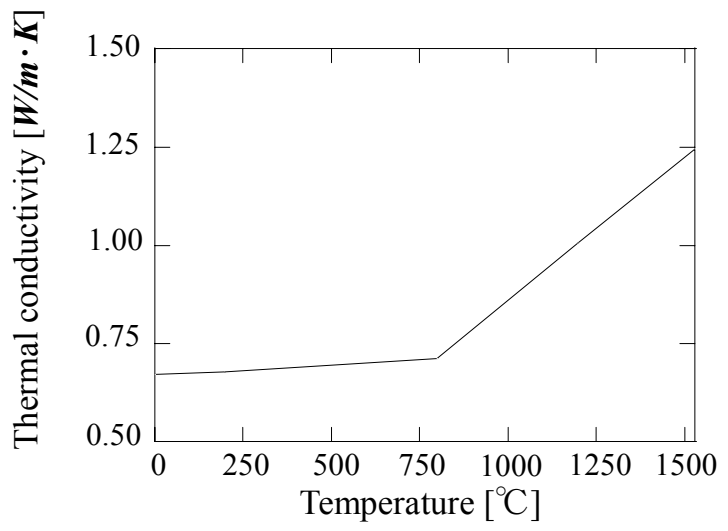

Fig.10 Thermal conductivity of sand mold

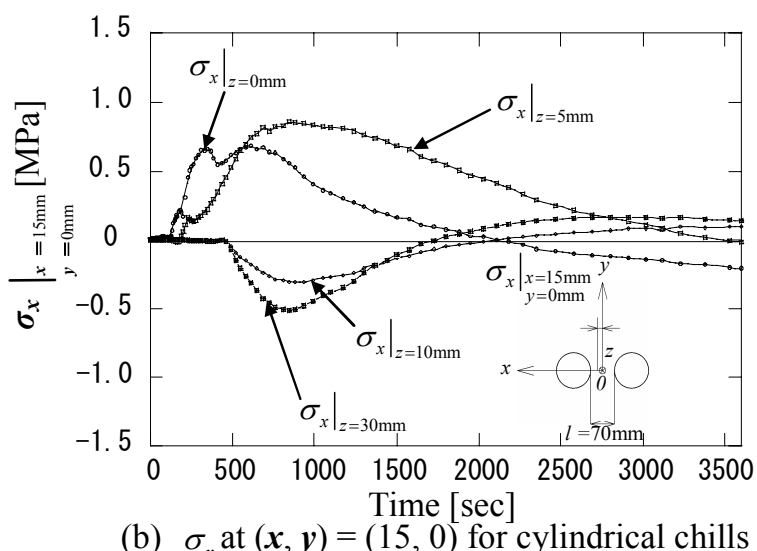

Fig.11 $\sigma_{x}$ vs. Time $(l=70 \mathrm{~mm})$ 


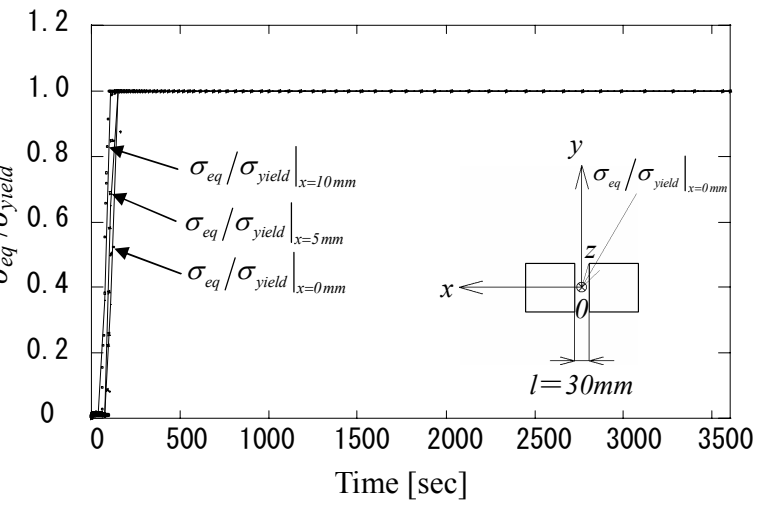

(a) Cubic chills $(l=30 \mathrm{~mm})$

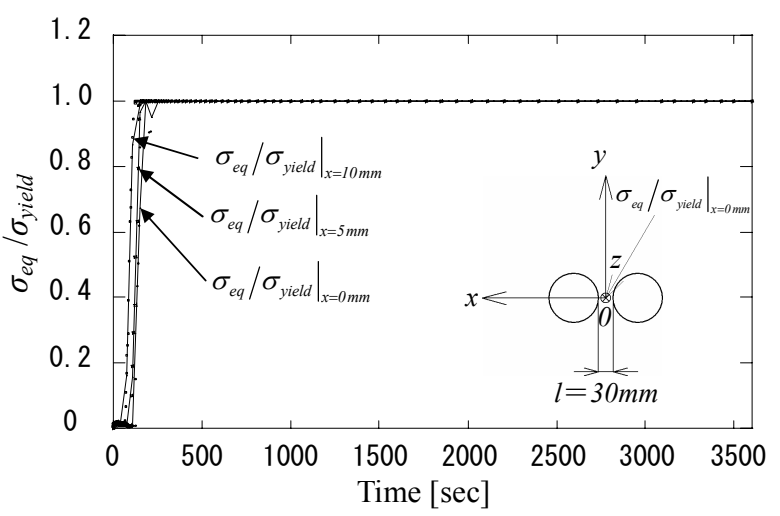

(b) Cylinder chills $(l=30 \mathrm{~mm})$

Fig.12 $\sigma_{\text {eq }} / \sigma_{\text {yield }}$ vs. Time $(l=30 \mathrm{~mm}, z=10 \mathrm{~mm})$

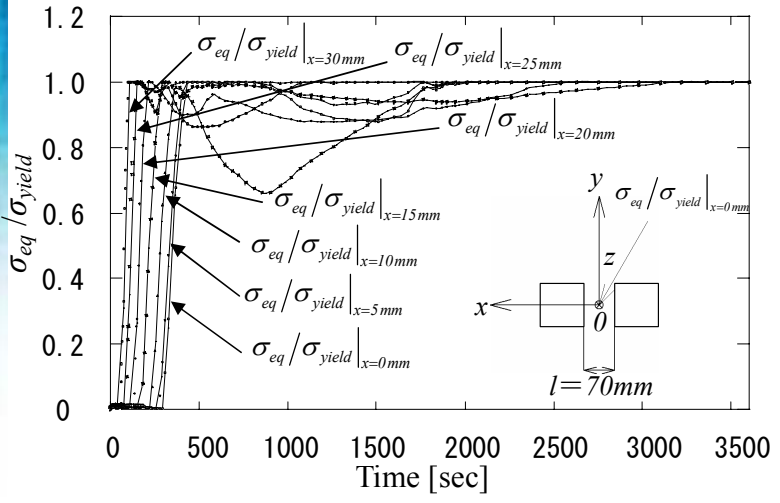

(a) Cubic chills $(l=70 \mathrm{~mm})$

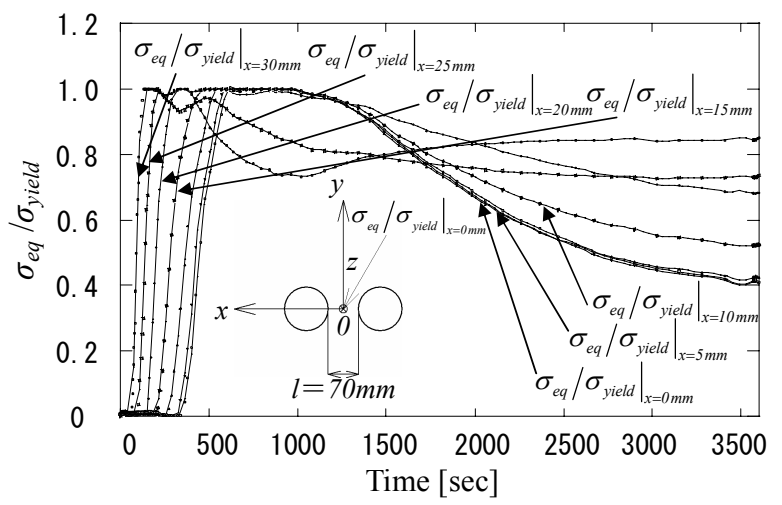

(b) Cylinder chills $(l=70 \mathrm{~mm})$

Fig.13 $\sigma_{\text {eq }} / \sigma_{\text {yield }}$ vs. Tim $m m, z=10 \mathrm{~mm}$ )

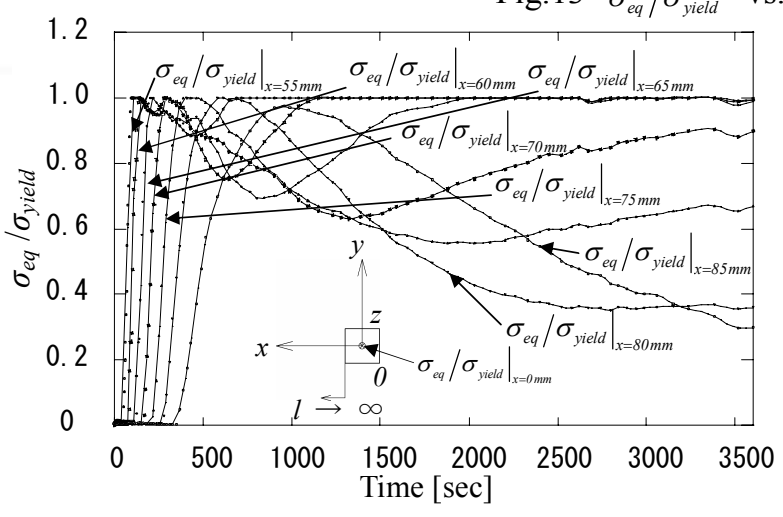

(a) Cubic chills $(l \rightarrow \infty)$

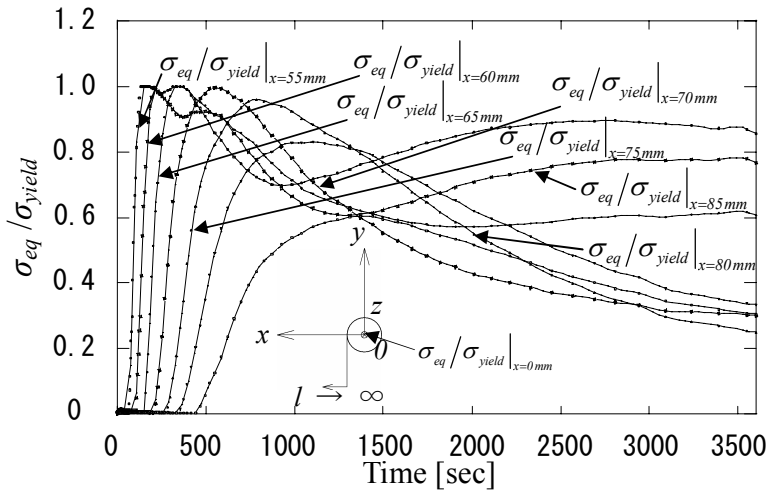

(b) Cylinder chills $(l \rightarrow \infty)$

Fig.14 $\sigma_{e q} / \sigma_{\text {yield }}$ vs. Time $(l \rightarrow \infty, z=10 \mathrm{~mm})$

relation for spacing $l=70 \mathrm{~mm}$. For two cubic chills with $l=70 \mathrm{~mm}$, cracks may appear because $\sigma_{e q} / \sigma_{\text {yield }}=$ unity. However, for two cylinder chills with $l=70 \mathrm{~mm}$, cracks may not appear because $\sigma_{e q} / \sigma_{\text {yield }}$ is less than unity. Figure 14 shows $\sigma_{\text {eq }} / \sigma_{\text {yield }}$ vs. time relation for spacing $l=$ infinity. For $l=$ infinity, cracks may not appear in both cases because $\sigma_{e q}$ is usually less than $\sigma_{\text {yield }}$. However, if the distance between two chills is too large, other types of defects such as shrinkage cavity and segregation may appear because cooling effect is not enough.

\subsection{Plastic regions between the two chills}

In Figs. 15 and 16, yielding regions between the two chills with space $l=70 \mathrm{~mm}$ are indicated. The yielding regions are on a plane $z=10 \mathrm{~mm}$ where the largest $\sigma_{x}$ appears. Figures 15 (a) and 16 (a) shows the regions when the maximum $\sigma_{x}$ appears. On the other hand, Figs 15 (b) and 16 (b) shows the regions after $600 \mathrm{sec}$ past after the time (a). Similar analysis has been performed when the two chills have a space $l=30 \mathrm{~mm}$. However, 
figures are omitted because plastic regions are always observed between the two chills. From Fig 15, it is found that a crack may appear because between the two cubic chills plastic regions are widely observed with a long time. However, from Fig.16, it is found that
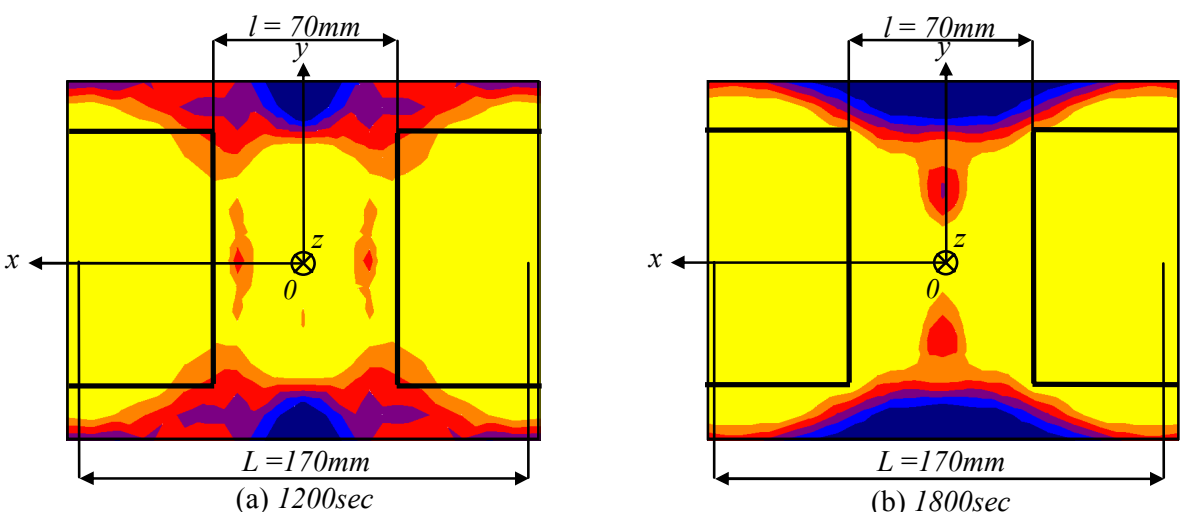

Fig. 15 Yielding Region (Cubic Chills, $l=70 \mathrm{~mm}, a=100 \mathrm{~mm}, t=100 \mathrm{~mm}, z=10 \mathrm{~mm}$ )

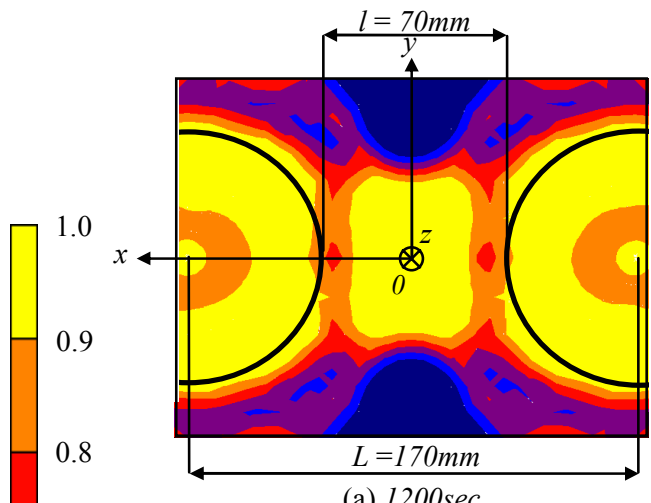

(a) $1200 \mathrm{sec}$

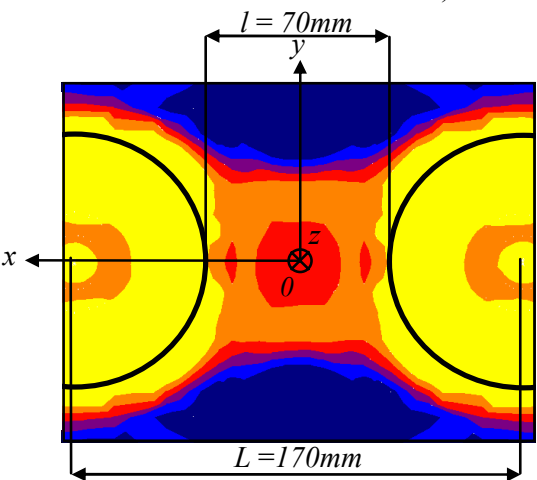

(b) $1800 \mathrm{sec}$

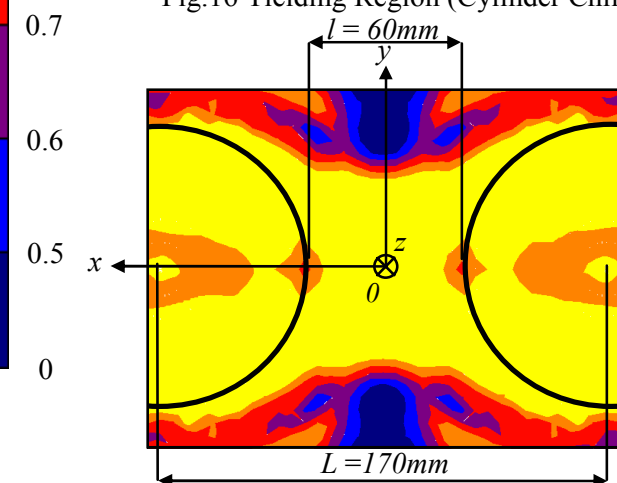

(a) $1200 \mathrm{sec}$

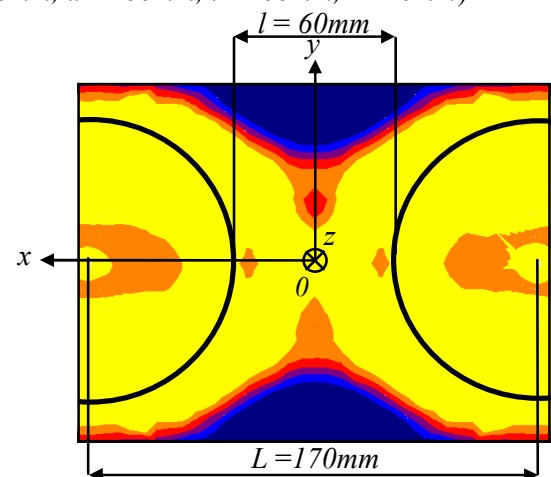

(b) $1800 \mathrm{sec}$

Fig. 17 Yielding Region (Cylinder Chills, $L=170 \mathrm{~mm}, d=110 \mathrm{~mm}, t=100 \mathrm{~mm}, z=10 \mathrm{~mm}$ )

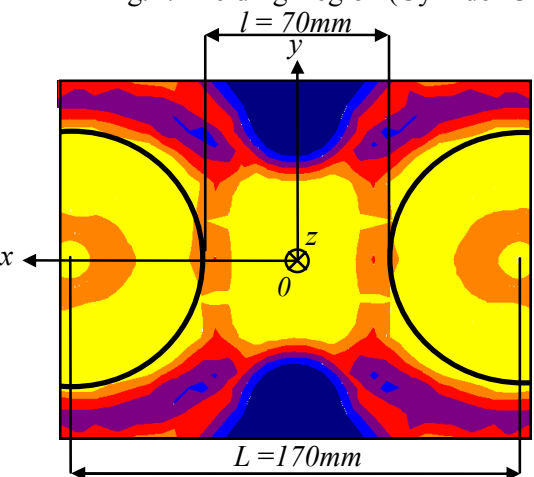

(a) $1200 \mathrm{sec}$

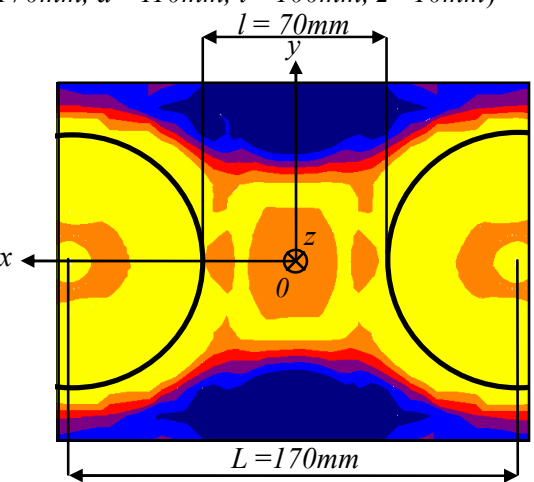

(b) $1800 \mathrm{sec}$

Fig. 18 Yielding Region (Cylinder Chills, $L=170 \mathrm{~mm}, d=100 \mathrm{~mm}, t=120 \mathrm{~mm}, z=10 \mathrm{~mm}$ ) 
between the two cylindrical chills plastic region are also observed but comparatively with a short time. Moreover, the plastic region is wider for two cubic chills.

\subsection{Relationship between the plastic region and contact area of two chills}

Figure 17 shows yielding regions between the two cylindrical chills at $z=10 \mathrm{~mm}$ when the diameter of cylindrical chills is changed from $100 \mathrm{~mm}$ to $110 \mathrm{~mm}$. In Fig.17, the contact area of the cylindrical chill with the diameter $110 \mathrm{~mm}$ is the same as the cubic chill with the dimension $a=100 \mathrm{~mm}$ in Fig.15. In Fig. 17 and Fig.15, the spaces between the two chills are the same as $L=170 \mathrm{~mm}$. From Fig. 17 and Fig. 15 , it is seen that there is no significant difference between the plastic regions under the same the contact area of the chill and the same space L. Therefore it may be concluded that the difference after $1800 \mathrm{sec}$ in Fig. 15 and Fig. 16 is mainly caused by the difference of the contact areas.

\subsection{Effect of height of chills on the plastic region}

Figure 18 shows yielding regions between the two cylindrical chills at $z=10 \mathrm{~mm}$ when the height of cylindrical chills is changed from $100 \mathrm{~mm}$ to $120 \mathrm{~mm}$. In Fig. 18 and Fig. 16, the same spacing $L=170 \mathrm{~mm}$ is assumed between the two chills. From Fig.18 and Fig.16, it is seen that the plastic region becomes wider by changing the height from $100 \mathrm{~mm}$ to $120 \mathrm{~mm}$. This is because higher chills cause more heat reduction from cast steel and result in larger thermal stresses.

\section{Conclusions}

The large-scale cast steel products have been used as fundamental components of structures in broad fields of industries such as power generation, construction, vessels, and automobiles. Since large-scale casting process needs longer time for cooling, three types of defects are often appearing and requiring a lot of money to repair. Recently, non-steady state heat-transfer analyses are found to be useful for predicting shrinkage cavity and segregation, which may be controlled by casting temperature distributions. However, crack-type defects, which may be controlled by thermal stress, cannot be eliminated successfully in the conventional approach.

In this paper, therefore, the finite element method was applied to simulating a casting process of a hummer used for press machinery, which manufactures bodies of automobiles. In this study, we have focused on how to predict cracks appearing at the hummer surface. A three-dimensional thermal elastic-plastic stress analysis was performed in connection with three-dimensional non-steady state heat transfer analysis, including interaction between the temperature and stress field ${ }^{(3)}$. Then, the thermal stress was investigated with varying geometrical parameters such as the spacing of chills, shape of the contact area, and height of the chills. The conclusions can be given in the following way.

(1) On the one hand, for cubic chill, cracks may appear when $l \leq 70 \mathrm{~mm}$ because yielding condition $\sigma_{e q} / \sigma_{\text {yield }}=$ unity appears for a long time. On the other hand, for cylindrical chill, cracks may not appear when $l \leq 70 \mathrm{~mm}$ because $\sigma_{\text {eq }} / \sigma_{\text {yield }}=$ unity only for a short time. Previous experience shows that cracks are more often observed between cubic chills compared with cylindrical chills when $l=70 \sim 90 \mathrm{~mm}$. The present calculations indicate the difference of thermal stress between the cubic and cylindrical chills significantly when $l=70 \mathrm{~mm}$.

(2) If the spacing of chill is large enough, for example, $l>70 \mathrm{~mm}$, cracks may not appear independent of chill shape because of short yielding time. However, shrinkage cavity and segregation may appear between the chills because cooling effect is not enough.

(3) If the contact area and spacing of the chills are nearly the same, there is no significant difference observed between the plastic regions of cubic and cylindrical chills. Therefore it may be concluded that the difference of cubic and cylindrical chills with the same dimension $100 \mathrm{~mm}$ is mainly caused by the difference of the contact areas.

(4) The size of plastic region between the chills increases with increasing the height of the chills under the same contact area and spacing. 
The above conclusions are derived from the analysis of the most fundamental two-chill model. And therefore, further investigation may be necessary to confirm those conclusions considering real arrangement and real number of the chills. However, as shown in conclusion (1) it may be concluded that two-chill model may explain some knowledge of crack-type defects in terms and provide new results of thermal stress.

\section{Acknowledgement}

The authors wish to express our thanks to the member of the research group, Mr. Tsuyunaru Masakazu for his kind help for FEM calculations.

\section{References}

(1) Niyama, E., Dr. Eng, Uchida, T., Morikawa, M., and Saito, S.,A Method of Shrinkage Prediction and Its Application to Steel Casting Practice, Imono, vol.54, N0.8(1982), pp.507-517.

(2) Narita, K., Taniguchi, M., On the Mechanism of Formation of the Inverted V Segregates in Killed Steel Ingots, Tetsu-to-Hagane, Vol.56, No.2(1970), pp.68-85(in Japanese).

(3) Kinoshita, K., Emi, T., Kasai, M., Thermal Elasto-plastic Stress Analysis of Solidifying Shell in Continuous Casting Mold, Tetsu-to-Hagane, Vol.65, No.14 (1979), pp.40-49(in Japanese).

(4) Yamamoto, S., Tashiro, Y., Hirose, Y., Kusano, K., Takebayashi, K., Saeki, K,, Solidification Analysis of Metal Steel Castings, Imono, Vol.57, No.1 (1985), pp.47-50(in Japanese).

(5) Salcudean, M., Abdullah, Z., On The Numerical Modelling of Heat Transfer During Solidification Processes, International Journal for Numerical Method in Engineering, Vol.25(1988), pp.445-473.

(6) Kinoshita, K., Emi, T., Kasai, M., Thermal Elasto-plastic Stress Analysis of Solidifying Shell in Continuous Casting Mold, Tetsu-to-Hagane, Vol.65, No.14 (1979), pp.40-49 (in Japanese).

(7) Yoshio, E., Kazuyoshi, S., and Masujiroh, H., Analysis of Thermal and Residual Stresses of a Low Alloy Cast Steel Ingot by Use of Viscoplastic Constitutive Equations Considering Phase Transformation, Tetsu-to-Hagane, Vol.78, No.14 (1992), pp.50-57 (in Japanese). 